OPEN ACCESS

Edited by:

Pradyumna Kumar Mishra, ICMR-National Institute for Research in Environmental Health, India

Reviewed by: Prasant Kumar Jena, Cedars Sinai Medical Center,

United States

Mary A. Markiewicz, University of Kansas Medical Center.

United States

Sriram Seshadri,

Nirma University, India

${ }^{*}$ Correspondence:

Reinhard Gruber

reinhard.gruber@meduniwien.ac.at

Specialty section:

This article was submitted to Inflammation,

a section of the journal

Frontiers in Immunology

Received: 10 March 2021 Accepted: 10 May 2021

Published: 31 May 2021

Citation: Apaza Alccayhuaman KA, Heimel $P$, Lee J-S, Tang/ S, Strauss FJ, Stähli A,

Matalová E and Gruber R (2021)

FasL Is Required for Osseous Healing in Extraction Sockets in Mice.

Front. Immunol. 12:678873.

doi: 10.3389/fimmu.2021.678873

\section{FasL Is Required for Osseous Healing in Extraction Sockets in Mice}

\author{
Karol Alí Apaza Alccayhuaman ${ }^{1,2}$, Patrick Heimel ${ }^{2,3,4}$, Jung-Seok Lee ${ }^{1,5}$, Stefan Tangl ${ }^{2,4}$, \\ Franz J. Strauss ${ }^{1,6,7}$, Alexandra Stähli ${ }^{8}$, Eva Matalová ${ }^{9}$ and Reinhard Gruber ${ }^{1,4,8^{*}}$ \\ 1 Department of Oral Biology, Medical University of Vienna, Vienna, Austria, ${ }^{2}$ Karl Donath Laboratory for Hard Tissue and \\ Biomaterial Research, School of Dentistry, Medical University of Vienna, Vienna, Austria, ${ }^{3}$ Ludwig Boltzmann Institute for \\ Experimental and Clinical Traumatology, Vienna, Austria, ${ }^{4}$ Austrian Cluster for Tissue Regeneration, Medical University of \\ Vienna, Vienna, Austria, ${ }^{5}$ Department of Periodontology, Research Institute for Periodontal Regeneration, College of \\ Dentistry, Yonsei University, Seoul, South Korea, ${ }^{6}$ Clinic of Reconstructive Dentistry, University of Zurich, Zurich, Switzerland, \\ ${ }^{7}$ Department of Conservative Dentistry, School of Dentistry, University of Chile, Santiago, Chile, ${ }^{8}$ Department of \\ Periodontology, School of Dental Medicine, University of Bern, Bern, Switzerland, ${ }^{9}$ Institute of Animal Physiology and \\ Genetics, Czech Academy of Sciences, Brno, Czechia
}

Fas ligand (FasL) is a member of the tumor necrosis factor (TNF) superfamily involved in the activation of apoptosis. Assuming that apoptosis is initiated after tooth extraction it is reasonable to suggest that FasL may play a pivotal role in the healing of extraction sockets. Herein, we tested the hypothesis of whether the lack of FasL impairs the healing of extraction sockets. To this end, we extracted upper right incisors of Fas $\mathrm{L}$ knockout (KO) mice and their wildtype (WT) littermates. After a healing period of two weeks, bone volume over total volume (BV/TV) via $\mu$ CT and descriptive histological analyses were performed. $\mu C T$ revealed that BV/TV in the coronal region of the socket amounted to $39.4 \%$ in WT and $21.8 \%$ in $\mathrm{KO}$, with a significant difference between the groups ( $\mathrm{p}=0.002)$. Likewise, in the middle region of the socket, BV/TV amounted to $50.3 \%$ in WT and $40.8 \%$ in $\mathrm{KO}$ $(p<0.001)$. In the apical part, however, no difference was noticed. Consistently, WT mice displayed a significantly higher median trabecular thickness and a lower trabecular separation when compared to the $\mathrm{KO}$ group at the coronal and central region of the socket. There was the overall tendency that in both, female and male mice, FasL affects bone regeneration. Taken together, these findings suggest that FasL deficiency may reduce bone regeneration during the healing process of extraction sockets.

Keywords: dentistry, bone regenaration, tooth extraction, fasl, knockout (KO), $\mu \mathrm{CT}$, histology

\section{INTRODUCTION}

FasL (CD178; CD95L; APO1L and TNF ligand superfamily member 6) belongs to the tumor necrosis factor (TNF) family and interacts with Fas (CD95; APO-1; TNFRSF6) receptor (1). The FasL/Fas pathway is the common initiator of an extrinsic apoptotic machinery engaged in the immune system (2-4) having the potential to affect the development of teeth (5) and bones (6-8). Fas and Fas ligand are present in the jaw bone and tooth germs of human fetuses (9). Moreover, mice homozygous for the FasL point mutation display an osteopetrotic phenotype in their long bones (10). These mice even showed an enhanced bone formation upon stimulation with demineralized bone and BMP-2 when compared to wildtype mice $(11,12)$. FasL when expressed 
by osteoblast controls osteoclast apoptosis $(13,14)$, number and activity (15). Considering that bone regeneration involves the coordinated activity of osteoclasts and particularly of osteoblasts, there is reason to suggest that FasL is required for the healing of tooth extraction sockets.

Healing of extraction sockets has become an important issue in dentistry particularly due to the increasing demand of dental implants as a therapy to replace missing teeth (16). The alveolar bone usually undergoes atrophy upon the tooth extraction (17-19), and various treatment regimens were developed and introduced for extraction socket grafting. However, histologic bone quality differs with varying degrees of new bone formation (20). Therefore, there has been a great interest to understand bone regeneration and the healing process of extraction sockets. Bone regeneration is a sequential process of events that partially recapitulates bone development involving cell apoptosis and the coordinated action of osteoblast and osteoclasts (21-23). Accumulating evidence suggests that the FasL/Fas system is involved in bone regeneration. For example, mice lacking Fas show delayed cartilage resorption and less bone in the fracture calluses (24). With respect to wound healing, the lack of FasL/Fas signaling impairs apoptosis in granulation tissue and mononuclear cells $(25,26)$. Thus, it seems conceivable that FasL is involved in the healing of extraction sockets.

The aim of the present study was, therefore, to examine whether or not the lack of FasL impairs the healing of extraction sockets. To test this assumption, we took advantage of the established FasL knockout mice along with a recent established tooth extraction model in mice (27). Based on a segmentation of the alveolar socket, it is possible to measure new bone formation, that in combination with histology of undecalcified thin ground sections, provides insights into the overall healing situation of the extraction socket. Based on this approach, we identified FasL as a molecular target involved in the bone regeneration and healing process of extraction sockets in rodents.

\section{MATERIAL AND METHODS}

\section{Study Design}

The Medical University of Vienna ethical review board for animal research approved the study protocol (GZ BMWFW-66.009/0359$\mathrm{V} / 3 \mathrm{~b} / 2018)$. The study was performed at the Department of Biomedical Research of the Medical University of Vienna in accordance with the NC3Rs ARRIVE guidelines. Mice homozygous for the Faslgld mutation (B6Smn.C3-Faslgld/J) were purchased from The Jackson Laboratory (Bar Harbor, ME) and housed in the Medical University of Vienna, Institute of Biomedical Research under specific-pathogen-free (SPF) conditions. FasL knockout mice and littermate controls (8-12 weeks, around $22 \mathrm{~g}$ ) underwent tooth extraction of the upper right incisor. The animals were maintained according to the animal welfare guidelines with free access to water and a standard diet (28).

\section{Tooth Extraction Model}

The tooth extraction model was performed as recently described (27). In brief, all animals received ketamine $100 \mathrm{mg} / \mathrm{kg}$
(AniMedica, Senden, Erlangen, Germany) and xylazine hydrochloride $5 \mathrm{mg} / \mathrm{kg}$ (Bayer Austria, Vienna, Austria) by intramuscular injection. Then, the head of the mouse was stabilized by holding the contralateral tooth with a tweezer. Next, with the aid of a stereomicroscope (Leica M651, Leica Microsystems, Wetzlar, Germany) under 16X magnification, the upper right incisor was luxated using disposable needles (HSW FINE-JECT ${ }^{\circledR}$, Tuttlingen, Germany) of different diameters $(0.4 \mathrm{~mm}, 0.6 \mathrm{~mm}$ and $0.8 \mathrm{~mm})$ as periotomes. After a proper luxation, the tooth was carefully extracted to avoid any root fracture using an Adson tweezer (Aesculap, Tuttlingen, Germany) and checked for integrity. For pain relief, buprenorphine $0.06 \mathrm{mg} / \mathrm{kg}$ s.c. (Temgesic ${ }^{\circledR}$, Reckitt and Colman Pharm., Hull, UK) and piritramide in drinking water ad lib was administered. The first 72 hours after surgery soft diet was provided. Mice were euthanized on day fourteen by cervical dislocation and each alveolar socket was subjected to micro computed tomographic $(\mu \mathrm{CT})$ and histological analysis.

\section{MicroCT Analysis}

After euthanasia, the heads were fixed in phosphate-buffered formalin (Roti-Histofix 4\%, Carl Roth, Karlsruhe, Germany). MicroCT scans were made using a Scanco $\mu$ CT 50 (Scanco Medical AG, Bruttisellen, Switzerland) at $90 \mathrm{kV} / 200 \mu \mathrm{A}$ with an isotropic resolution of $10 \mu \mathrm{m}$ and an integration time of $500 \mathrm{~ms}$. Using Amira 6.1.1 (Thermo Fisher Scientific, Waltham, USA), The image stacks were imported into Fiji for the posterior analysis (29, 30 ). The region of interest (ROI) was drawn using the polygon and freehand selection tools and saved using the ROI manager. To have a standardized position of the ROIs from all samples, four anatomical landmarks were set up, thereby dividing the alveolar socket in three regions (coronal, middle and apical) from the rearmost point to the most frontal point (Figure 1A). The percentage of Bone volume per Tissue volume (BV/TV), Trabecular thickness (Tb.Th) and Trabecular separation (Tb.Sp) were measured in the ROI with a threshold of $254 \mathrm{mgHA} / \mathrm{cm}^{3}$.

\section{Histological Analysis}

Ten samples were dehydrated with ascending alcohol grades and embedded in light-curing resin (Technovit 7200 VLC + BPO; Kulzer \& Co., Wehrheim, Germany). Blocks were further processed using Exakt cutting and grinding equipment (Exakt Apparatebau, Norderstedt, Germany). Thin-ground sections from all samples were prepared (31), in a plane parallel to the sagittal suture and through the middle of the alveolar socket and stained with Levai-Laczko dye (Figure 1B). The slices of around $100 \mu \mathrm{m}$ were scanned using an Olympus BX61VS digital virtual microscopy system (DotSlide 2.4, Olympus, Tokyo, Japan) with a 20x objective resulting in a resolution of $0.32 \mu \mathrm{m}$ per pixel and then evaluated.

\section{Statistical Analysis}

Statistical analysis was based on the data obtained from the microCT analysis. Median values and confidence intervals (CI) of the primary endpoint, bone volume (BV/TV) and secondary endpoints (Tb.Th and Tb.Sp) in the alveolar socket, between the two groups were compared with Mann-Whitney U test. Further analyses were performed comparing the mice gender and 


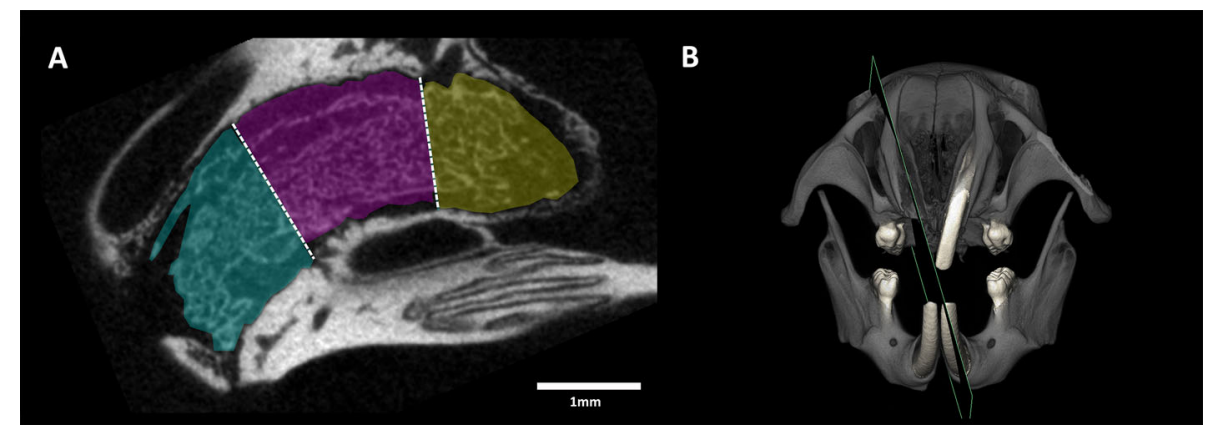

FIGURE 1 | Region of interests (ROI) of the extraction socket for the $\mu \mathrm{CT}$ analysis. (A) The ROls for the microCT analysis comprised the coronal (cyan), middle (purple) and apical (yellow) region through the entire volume of the tooth extraction site. (B) The plane oriented along the central alveolar socket was the reference for preparing the histological ground sections.

intragroup between WT and FasL KO using the Mann-Whitney U test. All the analyses were performed using Prism v7 (GraphPad Software, La Jollia, CA). Significance was set at $\mathrm{p}<0.05$.

\section{RESULTS}

\section{Micro CT Analysis of Bone Volume Per Tissue Volume (BV/TV)}

For the analysis a total of ten WT and ten FasL KO mice were used comprising five males and females in each group (Figure 2). Statistical analysis revealed that the median BV/TV in the coronal region of the socket was significantly higher $(\mathrm{p}=0.002)$ in the WT than in the KO group, with $39.4 \%$ (22.1 min; 52.3 max) versus 21.8\% (2.0 min; 41.0 max), respectively (Figures 2A-C). Likewise, in the middle region of the socket, the BV/TV in the WT was significantly higher $(\mathrm{p}<0.001)$ than in the $\mathrm{KO}$ group, with $50.3 \%$ (39.57 $\mathrm{min} ; 66.31 \mathrm{max}$ ) and 40.8\% (30.20 $\mathrm{min} ; 46.81 \mathrm{max}$ ), respectively (Figure 2D). The median changes of BV/TV in the apical part of the socket failed to reach the level of significance $(p=0.796$; Figure 2E). Further analysis was performed comparing female and male mice. In the coronal and center region, the WT female $(\mathrm{p}=0.016 ; \mathrm{p}=0.008)$ and WT male mice $(\mathrm{p}=0.032 ; \mathrm{p}=0.056)$ displayed higher bone formation compared to the respective FasL $\mathrm{KO}$ mice. Intragroup comparisons revealed in the middle region a remarkable difference $(\mathrm{p}=0.008)$ between the male and female WT mice (Figure 2D), while in the other groups there were no gender differences. These findings suggest that FasL is involved in the formation of new bone volume in the extraction socket of female and male mice.

\section{Micro CT Analysis of Trabecular Thickness (TbTh) and Trabecular Separation (TbSp)}

In support of the bone volume fraction, the median trabecular thickness (TbTh) in the coronal region of the socket was significantly $(\mathrm{p}=0.002)$ higher in WT than in $\mathrm{KO}$, with $0.04 \mathrm{~mm}$ (0.02 min; $0.06 \mathrm{max}$ ) versus $0.02 \mathrm{~mm}$ (0.002 min; $0.04 \mathrm{max}$ ), respectively (Figure 3A). This significant difference $(\mathrm{p}<0.001)$ was also observed in the middle part of the socket, with
$0.05 \mathrm{~mm}$ (0.04 min; $0.07 \mathrm{max})$ in WT and $0.04 \mathrm{~mm}(0.03 \mathrm{~min}$; $0.04 \mathrm{max}$ ) in $\mathrm{KO}$, respectively (Figure 3B) but not in the apical part of the socket (Figure 3C). Consistently, coronal trabecular separation $(\mathrm{TbSp})$ was significant higher $(\mathrm{p}=0.003)$ in WT than in KO mice, with $0.09 \mathrm{~mm}$ (0.06 min; $0.14 \mathrm{max}$ ) and $0.17 \mathrm{~mm}$ (0.07 $\mathrm{min} ; 0.23 \mathrm{max}$ ), respectively (Figure 3A). Similarly, this difference was also significant $(\mathrm{p}=0.004)$ in the middle part, $0.07 \mathrm{~mm}$ (0.04 min; $0.13 \mathrm{max}$ ) versus $0.09 \mathrm{~mm}$ (0.06 min; 0.15 $\max$ ), respectively (Figure 3B). In the apical part, nonetheless, there were no significant differences (Figure 3C). Considering mouse gender, there was the overall tendency that female and male mice, were similarly affected by the lack of FasL in the coronal and middle part of the extraction sockets (Figures 3A, B). Intragroup comparisons revealed that WT and $\mathrm{KO}$ female mice when compared to their male littermates, have a denser trabecular network reaching the level of significance in the middle region (Figure 3B). Taken together, these observations indicate that FasL is partially required for the proper formation of trabecular structures in both genders.

\section{Histological Analyses}

Newly generated woven bone was observed in the WT and FasL KO mice (Figure 4). This woven bone formed a trabecular network with random orientation surrounded either by thin layers of parallel fibered bone or thin layers of unmineralized matrix osteoid. Newly formed bone was located next to the coronally bone walls and in the middle, filling almost completely the alveolar defect, while the FasL KO mice exhibited a trabecular bone enclosing bigger spaces formed between. We also observed signs of growing teeth denoted by the formation of new dentine and enamel in both, the FasL KO and WT mice (Figure 5). These structures, nevertheless, were excluded from the $\mu \mathrm{CT}$ analysis by segmentation.

\section{DISCUSSION}

The present pre-clinical study revealed that the lack of FasL attenuates the healing process of extraction socket in female and male mice. This research was inspired by the fact that FasL is a 


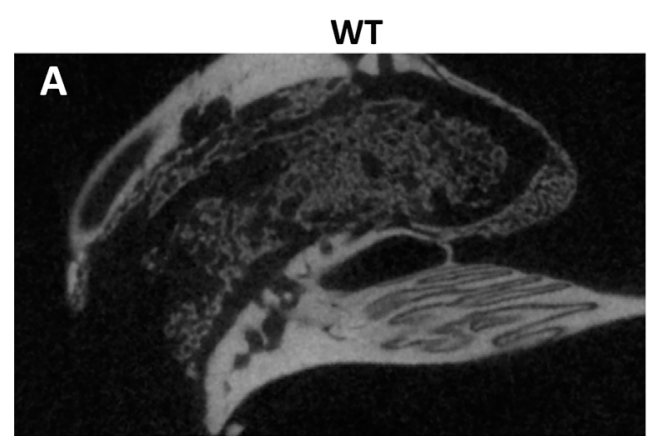

C

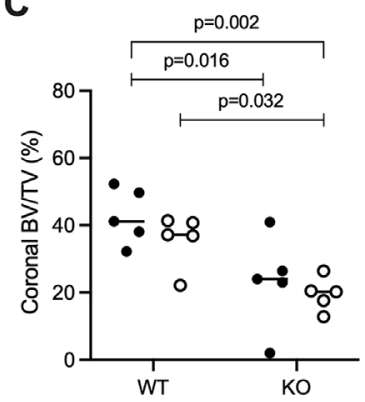

D

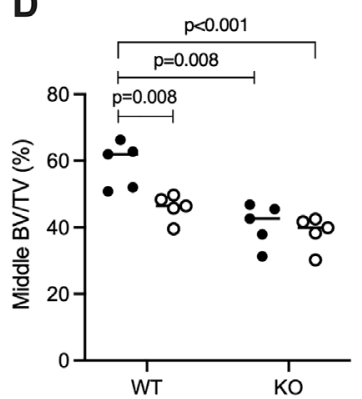

FasL KO

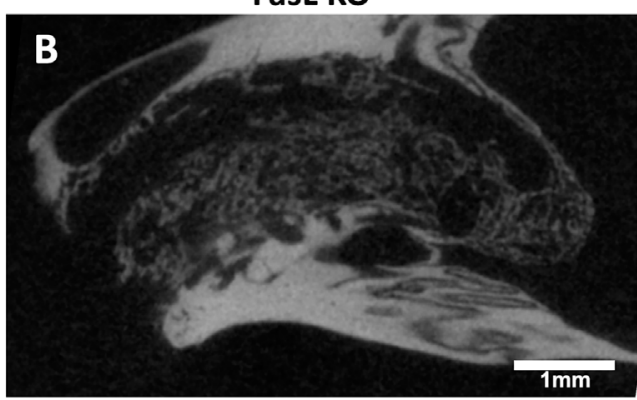

E

FIGURE 2 | Lack of FasL attenuates regeneration of the extraction socket. Sagittal view of the alveolar socket depicts the WT (A) and FasL KO mice (B). Quantitative analysis of the bone volume per tissue volume (BV/TV) displayed higher amounts of new bone volume in the WT mice in the coronal (C) and middle part (D) of the extraction socket compared to FasL KO mice. The apical region revealed no significant differences in BV/TV between WT and FasL KO mice (E). Statistical analysis was based on Mann-Whitney $U$ test, $P$ values are given where there was significant differences. The bars show the median and female (black dots) and male mice (white dots) are distributed in the dot plots for the WT and KO group.
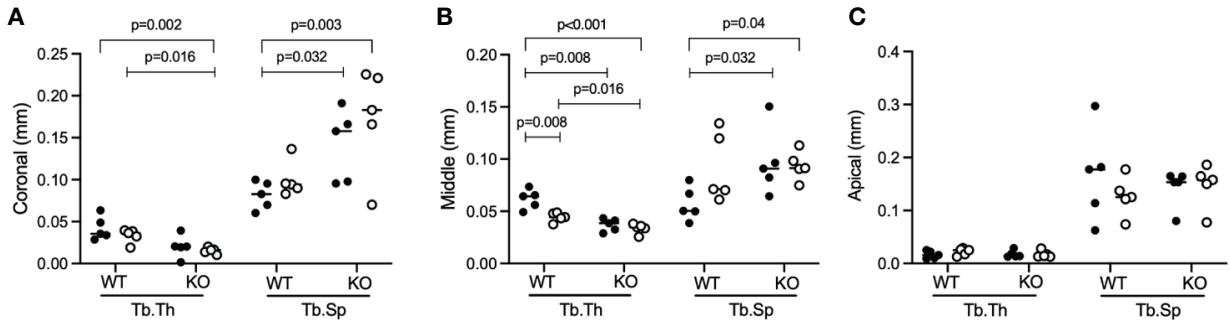

FIGURE 3 | Trabecular thickness (TbTh) and trabecular separation (TbSp) in the extraction sockets. FasL KO mice shows lower Tb.Th and higher Tb.Sp compared to WT mice in the coronal (A) and middle part (B) while no differences were observed in the apical part (C). Statistical analysis was based on Mann-Whitney $U$ test, $P$ values are given where was found significant differences. The bars show the median with female (black dots) and male mice (white dots) are distributed in the dot plots.

central regulator of apoptosis (2-4) having a major impact on bone cells life cycle thereby affecting osteoblasts and osteoclasts during bone remodeling. FasL is a key target for estrogen to control osteoblast-mediated osteoclast apoptosis (13-15). FasL was reported to delay cartilage resorption and bone formation in the fracture calluses (24) and wound healing. Moreover, FasL/Fas signaling controls apoptosis in granulation tissue and mononuclear cells $(25,26)$. To the best of the authors knowledge, the impact of FasL on bone regeneration, and in particular the intramembranous ossification upon tooth extraction inside the remaining alveolus, had not been investigated. Assuming that dying cells upon tooth extraction are presumably responsible for triggering the signals for repair and regeneration, we raised the hypothesis that the lack of FasL impairs the overall capacity of bone regeneration. Hereby we report that female and male mice deficient in FasL, show less bone formation in extraction sockets as compared to WT mice. This finding supports the notion that FasL is required for the bone healing process of extraction sockets.

If we compare the present findings to those of others, our data are in line with the critical involvement of FasL in bone formation. For example, embryonic and early 6-week postnatal FasL knockout mice showed less mandibular and alveolar bone compared to WT littermates $(32,33)$. Consistently, in 22-week old mice, whole genome FasL KO mice have less trabecular and 

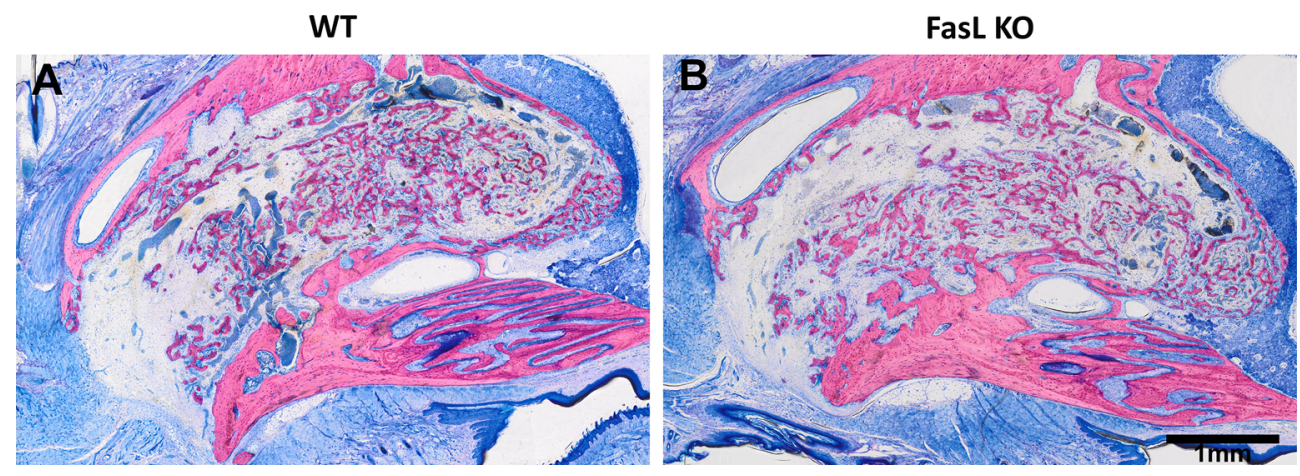

FIGURE 4 | The features of the newly formed bone were similar for the WT (A) and the FasL KO mice (B). Overview photomicrographs (2x) depicting the woven network.
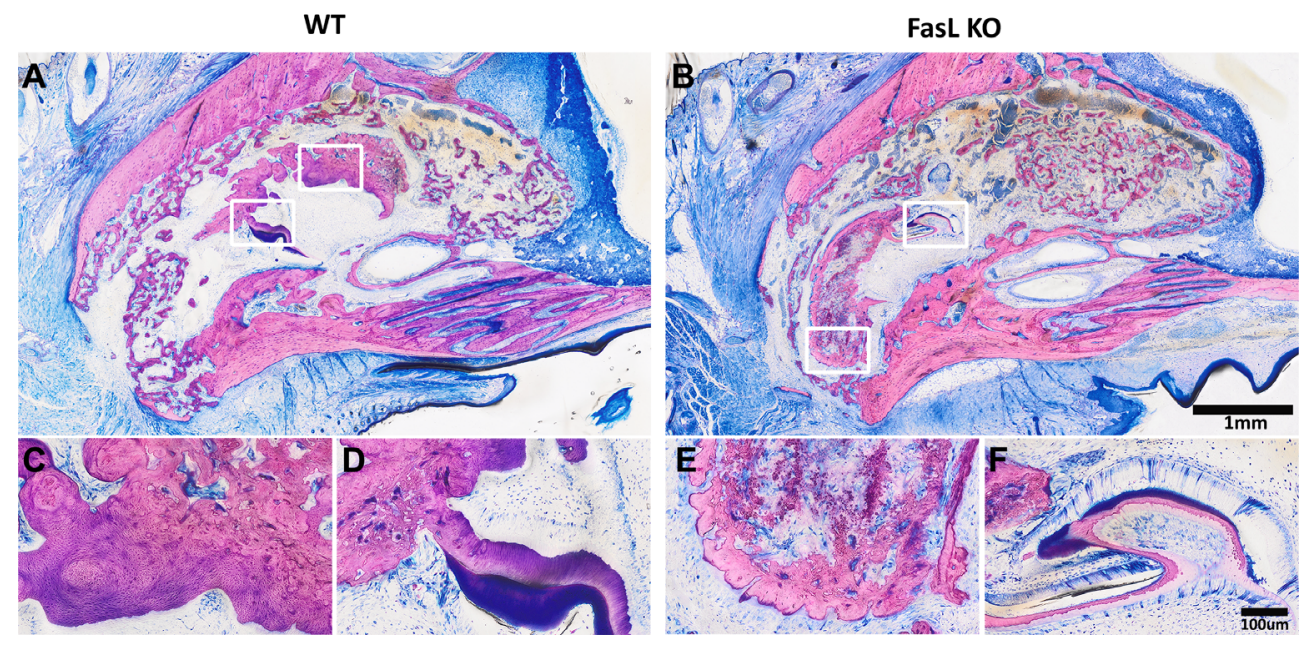

FIGURE 5 | The WT (A) and The FasL KO (B) mice revealed a structure like a growing tooth located at different areas of the alveolar socket in the overview image (2x). A higher magnification (20x) evidenced the "osteodentin mass" with dentin tubules (C, E) and enamel structure (D, F).

cortical bone in the axial and appendicular skeleton compared to their WT littermates (34). Even osteoblast progenitor/osteoblastspecific FasL-deficient mice showed markedly reduced bone density and structural parameters in the femurs (15). Our findings that FasL knockout mice showed less bone formation in the alveolar socket upon tooth extraction compared to the WT littermates are consistent with the relevance of FasL in bone formation. Furthermore, these findings are largely in agreement with the observation that already after two weeks healing, the extraction socket of incisors is almost completely filled with an immature woven bone-like tissue $(27,35)$.

The present study has a number of limitations. In the knockout mice, FasL is missing in all cells, meaning that we cannot draw conclusions whether or not the observed effects are caused by osteoblast or osteoclasts. It is plausible that the lack of FasL affects angiogenesis, implying that the impaired bone regeneration observed in the $\mathrm{KO}$ mice, is rather a consequence of a reduced supply of osteogenic progenitor cells (36). Future studies should therefore take advantage of conditional knockout models where FasL is deleted in specific cells types, for example with osteoblast progenitor/osteoblast-specific FasL-deficient mice (15). Thus, the origin of FasL capable of driving the FasLdependent apoptosis- or other apoptosis-independent responses during bone regeneration remains to be elucidated. Another study limitation was that we could not avoid sites with new tooth formation. The present findings might also serve for researchers asking if overexpression of FasL can support bone regeneration, for example by implementing the respective agonists (37) or using a transgenic FasL mouse model (38). It would also be interesting to know why female compared to male WT mice, show more a pronounced healing of extraction sockets. This was unexpected since male muscle-derived stem cells regenerated more bone than female cells in a calvaria defect (39). Nevertheless, the estrogen receptor beta is required for proper healing in female mice that 
however, does not rule out that it is also required in male mice (40). Moreover, ovariectomy impairs bone formation in drill-hole defects, but this setting does not allow a gender comparison (41). Hence, future research could focus more on the impact of gender on the healing of extraction sockets.

Future research should further use the FasL model to investigate fracture healing, as the impact of FasL on endochondral bone formation is not necessarily reflected by the tooth extraction model of intramembranous ossification that was used $(21,23)$. In fact, it is unclear whether a tooth extraction model represents intramembranous ossification in other anatomical regions that are perhaps more representative for the appendicular skeleton, beyond the field of dentistry. Our model, however, seems to be suitable to better understand the biology of the healing of extraction sockets and presumably also the osseointegration of dental implants that follow the same conserved sequence of events (42). It can be speculated that targeting the FasL system could be a therapeutic option to boost osseointegration, nevertheless, this would require data showing that pushing physiological FasL signaling enhances the bone regeneration (37). Certainly, the present research is a further step towards FasL-signaling in bone regeneration.

In conclusion, these data suggest that FasL is required for bone regeneration during the healing process of tooth extraction sockets.

\section{DATA AVAILABILITY STATEMENT}

The original contributions presented in the study are included in the article/supplementary material. Further inquiries can be directed to the corresponding author.

\section{REFERENCES}

1. Suda T, Takahashi T, Golstein P, Nagata S. Molecular Cloning and Expression of the Fas Ligand, A Novel Member of the Tumor Necrosis Factor Family. Cell (1993) 75:1169-78. doi: 10.1016/0092-8674(93)90326-L

2. Tsutsui H, Nakanishi K, Matsui K, Higashino K, Okamura H, Miyazawa Y, et al. IFN-Gamma-Inducing Factor Up-Regulates Fas Ligand-Mediated Cytotoxic Activity of Murine Natural Killer Cell Clones. J Immunol (1996) 157:3967-73.

3. Griffith TS, Brunner T, Fletcher SM, Green DR, Ferguson TA. Fas LigandInduced Apoptosis as a Mechanism of Immune Privilege. Science (1995) 270:1189-92. doi: 10.1126/science.270.5239.1189

4. Nagata S. Apoptosis by Death Factor. Cell (1997) 88:355-65. doi: 10.1016/ S0092-8674(00)81874-7

5. Matalova E, Svandova E, Tucker AS. Apoptotic Signaling in Mouse Odontogenesis. OMICS (2012) 16:60-70. doi: 10.1089/omi.2011.0039

6. Kovacic N, Lukic IK, Grcevic D, Katavic V, Croucher P, Marusic A. The Fas/ Fas Ligand System Inhibits Differentiation of Murine Osteoblasts But has a Limited Role in Osteoblast and Osteoclast Apoptosis. J Immunol (2007) 178:3379-89. doi: 10.4049/jimmunol.178.6.3379

7. Josefsen D, Myklebust JH, Lynch DH, Stokke T, Blomhoff HK, Smeland EB. Fas Ligand Promotes Cell Survival of Immature Human Bone Marrow CD34+ CD38- Hematopoietic Progenitor Cells by Suppressing Apoptosis. Exp Hematol (1999) 27:1451-9. doi: 10.1016/S0301-472X(99)00073-9

8. Rippo MR, Babini L, Prattichizzo F, Graciotti L, Fulgenzi G, Tomassoni Ardori F, et al. Low FasL Levels Promote Proliferation of Human Bone Marrow-Derived Mesenchymal Stem Cells, Higher Levels Inhibit Their Differentiation Into Adipocytes. Cell Death Dis (2013) 4:e594. doi: 10.1038/cddis.2013.115

9. Hatakeyama S, Tomichi N, Ohara-Nemoto Y, Satoh M. The Immunohistochemical Localization of Fas and Fas Ligand in Jaw Bone and Tooth Germ of Human Fetuses. Calcif Tissue Int (2000) 66:330-7. doi: 10.1007/s002230010069

\section{ETHICS STATEMENT}

The animal study was reviewed and approved by Austrian Federal Ministry of Education, Science and Research.

\section{AUTHOR CONTRIBUTIONS}

RG and EM contributed to the conception and design of the study. KAAA and PH work on the measurements of the data and organized the database. RG and KAAA wrote the first draft of the manuscript. FS, ST, and JL wrote sections of the manuscript. All authors contributed to the article and approved the submitted version.

\section{FUNDING}

This research project is funded by a grant from the Austrian Science Fund (FWF) (4072-B28) joint with the Czech Science Foundation (GACR) (19-29667L). KAAA is supported by an Osteology Research Scholarship.

\section{ACKNOWLEDGMENTS}

Authors thank Prof. Ulrike Kuchler for taking responsibility for the animal experiment.

10. Katavic V, Lukic IK, Kovacic N, Grcevic D, Lorenzo JA, Marusic A. Increased Bone Mass Is a Part of the Generalized Lymphoproliferative Disorder Phenotype in the Mouse. J Immunol (2003) 170:1540-7. doi: 10.4049/ jimmunol.170.3.1540

11. Katavic V, Grcevic D, Lukic IK, Vucenik V, Kovacic N, Kalajzic I, et al. NonFunctional Fas Ligand Increases the Formation of Cartilage Early in the Endochondral Bone Induction by rhBMP-2. Life Sci (2003) 74:13-28. doi: 10.1016/j.lfs.2003.06.031

12. Mori S, Nose M, Chiba M, Narita K, Kumagai M, Kosaka H, et al. Enhancement of Ectopic Bone Formation in Mice With a Deficit in FasMediated Apoptosis. Pathol Int (1997) 47:112-6. doi: 10.1111/j.1440-1827. 1997.tb03729.x

13. Krum SA, Miranda-Carboni GA, Hauschka PV, Carroll JS, Lane TF, Freedman LP, et al. Estrogen Protects Bone by Inducing Fas Ligand in Osteoblasts to Regulate Osteoclast Survival. EMBO J (2008) 27:535-45. doi: 10.1038/sj.emboj.7601984

14. Nakamura T, Imai Y, Matsumoto T, Sato S, Takeuchi K, Igarashi K, et al. Estrogen Prevents Bone Loss Via Estrogen Receptor Alpha and Induction of Fas Ligand in Osteoclasts. Cell (2007) 130:811-23. doi: 10.1016/ j.cell.2007.07.025

15. Wang L, Liu S, Zhao Y, Liu D, Liu Y, Chen C, et al. Osteoblast-Induced Osteoclast Apoptosis by Fas Ligand/FAS Pathway Is Required for Maintenance of Bone Mass. Cell Death Differ (2015) 22:1654-64. doi: 10.1038/cdd.2015.14

16. Jung RE, Zembic A, Pjetursson BE, Zwahlen M, Thoma DS. Systematic Review of the Survival Rate and the Incidence of Biological, Technical, and Aesthetic Complications of Single Crowns on Implants Reported in Longitudinal Studies With a Mean Follow-Up of 5 Years. Clin Oral Implants Res (2012) 23(Suppl 6):2-21. doi: 10.1111/j.1600-0501.2012.02547.x

17. Couso-Queiruga E, Stuhr S, Tattan M, Chambrone L, Avila-Ortiz G. PostExtraction Dimensional Changes: A Systematic Review and Meta-Analysis. J Clin Periodontol (2021) 48:126-44. doi: 10.1111/jcpe.13390 
18. Tan WL, Wong TL, Wong MC, Lang NP. A Systematic Review of PostExtractional Alveolar Hard and Soft Tissue Dimensional Changes in Humans. Clin Oral Implants Res (2012) 23(Suppl 5):1-21. doi: 10.1111/j.16000501.2011.02375.x

19. Schropp L, Wenzel A, Kostopoulos L, Karring T. Bone Healing and Soft Tissue Contour Changes Following Single-Tooth Extraction: A Clinical and Radiographic 12-Month Prospective Study. Int J Periodontics Restorative Dent (2003) 23:313-23. doi: 10.1016/j.prosdent.2003.10.022

20. Koo TH, Song YW, Cha JK, Jung UW, Kim CS, Lee JS. Histologic Analysis Following Grafting of Damaged Extraction Sockets Using Deproteinized Bovine or Porcine Bone Mineral: A Randomized Clinical Trial. Clin Oral Implants Res (2020) 31:93-102. doi: 10.1111/clr.13557

21. Einhorn TA, Gerstenfeld LC. Fracture Healing: Mechanisms and Interventions. Nat Rev Rheumatol (2015) 11:45-54. doi: 10.1038/nrrheum.2014.164

22. Gruber R, Koch H, Doll BA, Tegtmeier F, Einhorn TA, Hollinger JO. Fracture Healing in the Elderly Patient. Exp Gerontol (2006) 41:1080-93. doi: 10.1016/ j.exger.2006.09.008

23. Claes L, Recknagel S, Ignatius A. Fracture Healing Under Healthy and Inflammatory Conditions. Nat Rev Rheumatol (2012) 8:133-43. doi: 10.1038/nrrheum.2012.1

24. Al-Sebaei MO, Daukss DM, Belkina AC, Kakar S, Wigner NA, Cusher D, et al. Role of Fas and Treg Cells in Fracture Healing as Characterized in the FasDeficient (Lpr) Mouse Model of Lupus. J Bone Miner Res (2014) 29:1478-91. doi: 10.1002/jbmr.2169

25. Li Y, Takemura G, Kosai K, Takahashi T, Okada H, Miyata S, et al. Critical Roles for the Fas/Fas Ligand System in Postinfarction Ventricular Remodeling and Heart Failure. Circ Res (2004) 95:627-36. doi: 10.1161/01.RES. 0000141528.54850.bd

26. Guan DW, Ohshima T, Kondo T. Immunohistochemical Study on Fas and Fas Ligand in Skin Wound Healing. Histochem J (2000) 32:85-91. doi: 10.1023/A:1004058010500

27. Strauss FJ, Stähli A, Kobatake R, Tangl S, Heimel P, Apaza Alccayhuaman KA, et al. miRNA-21 Deficiency Impairs Alveolar Socket Healing in Mice. J Periodontol (2020) 91(12):1664-72. doi: 10.1002/JPER.19-0567

28. Kilkenny C, Browne WJ, Cuthill IC, Emerson M, Altman DG. Improving Bioscience Research Reporting: The ARRIVE Guidelines for Reporting Animal Research. PloS Biol (2010) 8:e1000412. doi: 10.1371/journal.pbio.1000412

29. Schindelin J, Arganda-Carreras I, Frise E, Kaynig V, Longair M, Pietzsch T, et al. Fiji: An Open-Source Platform for Biological-Image Analysis. Nat Methods (2012) 9:676-82. doi: 10.1038/nmeth.2019

30. Schindelin J, Rueden CT, Hiner MC, Eliceiri KW. The ImageJ Ecosystem: An Open Platform for Biomedical Image Analysis. Mol Reprod Dev (2015) 82:518-29. doi: 10.1002/mrd.22489

31. Donath K, Breuner G. A Method for the Study of Undecalcified Bones and Teeth With Attached Soft Tissues. The Sage-Schliff (Sawing and Grinding) Technique. J Oral Pathol (1982) 11:318-26. doi: 10.1111/j.1600-0714.1982.tb00172.x

32. Svandova E, Sadoine J, Vesela B, Djoudi A, Lesot H, Poliard A, et al. GrowthDependent Phenotype in FasL-Deficient Mandibular/Alveolar Bone. J Anat (2019) 235:256-61. doi: 10.1111/joa.13015
33. Svandova E, Vesela B, Lesot H, Sadoine J, Poliard A, Matalova E. Fasl Modulates Expression of Mmp2 in Osteoblasts. Front Physiol (2018) 9:1314. doi: 10.3389/fphys.2018.01314

34. Kim HN, Ponte F, Nookaew I, Ucer Ozgurel S, Marques-Carvalho A, Iyer S, et al. Estrogens Decrease Osteoclast Number by Attenuating Mitochondria Oxidative Phosphorylation and ATP Production in Early Osteoclast Precursors. Sci Rep (2020) 10:11933. doi: 10.1038/s41598-020-68890-7

35. Vieira AE, Repeke CE, Ferreira Junior Sde B, Colavite PM, Biguetti CC, Oliveira RC, et al. Intramembranous Bone Healing Process Subsequent to Tooth Extraction in Mice: Micro-Computed Tomography, Histomorphometric and Molecular Characterization. PloS One (2015) 10: e0128021. doi: 10.1371/journal.pone.0128021

36. Sivaraj KK, Adams RH. Blood Vessel Formation and Function in Bone. Development (2016) 143:2706-15. doi: 10.1242/dev.136861

37. Chodorge M, Zuger S, Stirnimann C, Briand C, Jermutus L, Grutter MG, et al. A Series of Fas Receptor Agonist Antibodies That Demonstrate an Inverse Correlation Between Affinity and Potency. Cell Death Differ (2012) 19:118795. doi: $10.1038 /$ cdd.2011.208

38. Yang J, Jones SP, Suhara T, Greer JJ, Ware PD, Nguyen NP, et al. Endothelial Cell Overexpression of Fas Ligand Attenuates Ischemia-Reperfusion Injury in the Heart. J Biol Chem (2003) 278:15185-91. doi: 10.1074/jbc. M211707200

39. Scibetta AC, Morris ER, Liebowitz AB, Gao X, Lu A, Philippon MJ, et al. Characterization of the Chondrogenic and Osteogenic Potential of Male and Female Human Muscle-Derived Stem Cells: Implication for Stem Cell Therapy. J Orthop Res (2019) 37:1339-49. doi: 10.1002/jor.24231

40. He YX, Liu Z, Pan XH, Tang T, Guo BS, Zheng LZ, et al. Deletion of Estrogen Receptor Beta Accelerates Early Stage of Bone Healing in a Mouse Osteotomy Model. Osteoporos Int (2012) 23:377-89. doi: 10.1007/s00198-011-1812-X

41. He YX, Zhang G, Pan XH, Liu Z, Zheng LZ, Chan CW, et al. Impaired Bone Healing Pattern in Mice With Ovariectomy-Induced Osteoporosis: A DrillHole Defect Model. Bone (2011) 48:1388-400. doi: 10.1016/j.bone. 2011.03.720

42. Vasak C, Busenlechner D, Schwarze UY, Leitner HF, Munoz Guzon F, Hefti T, et al. Early Bone Apposition to Hydrophilic and Hydrophobic Titanium Implant Surfaces: A Histologic and Histomorphometric Study in Minipigs. Clin Oral Implants Res (2014) 25:1378-85. doi: 10.1111/clr.12277

Conflict of Interest: The authors declare that the research was conducted in the absence of any commercial or financial relationships that could be construed as a potential conflict of interest.

Copyright (C) 2021 Apaza Alccayhuaman, Heimel, Lee, Tangl, Strauss, Stähli, Matalova and Gruber. This is an open-access article distributed under the terms of the Creative Commons Attribution License (CC BY). The use, distribution or reproduction in other forums is permitted, provided the original author(s) and the copyright owner(s) are credited and that the original publication in this journal is cited, in accordance with accepted academic practice. No use, distribution or reproduction is permitted which does not comply with these terms. 